\title{
ASPECTOS BÁSICOS DE ENFERMAGEM NO PÊNFIGO FOLIÁCEO SUL AMERICANO
}

Yoriko Kamiyama*

KAMIYAMA, Y. Aspectos básicos de enfermagem no Pênfigo Foliáceo Sul-Americano. Rev. Esc. Enf. 15(3):257-266, 1981.

A autora analisa a problemática do Pênfigo Foliáceo Sul-Americano, sua epidemiologia, diagnóstico, tratamento e profilaxia. Discorre sobre os principais problemas do paciente acometido por essa afecção e os aspectos básicos da assistência de enfermagem a esse tipo de doente.

\section{INTRODUÇÃO}

São denominadas Pênfigos todas as dermatoses caracterizadas por erupções bolhosas conseqüentes ao rompimento de pontes intercelulares da camada de Malpighi. ${ }^{7}$

Segundo LEME ${ }^{5}$, os Pênfigos classificam-se em 4 grandes grupos: Pênfigos Congênitos, Sintomáticos, Verdadeiros e Dermatite Herpetiforme. Cada um dos 4 grupos abrange grande número de condições patológicas as quais são apresentadas no Quadro 1.

Dos Pênfigos verdadeiros, o tipo Foliáceo Sul-Americano é o de maior significado médico-sanitário no Brasil.

Incide quase que exclusivamente no Brasil e países limítrofes e é considerado moléstia de grande interesse nacional pelos especialistas brasileiros. ${ }^{6}$

Além disso, é doença tropical muito pouco estudada nos demais países, o que torna grande a responsabilidade de médicos, enfermeiros e outros profissionais da área de saúde desses países, em especial do Brasil, quanto ao estudo do diagnóstico, da terapêutica, da profilaxia e da assistência aos pacientest portadores desse mal. 5,6

O Ministério da Saúde, através da portaria $n .^{\circ} 6$ de 7 de março de 1979, baixou normas técnicas para diagnóstico, tratamento e controle do Pênfigo Foliáceo Sul-americano. $* *$

É doença de elevada incidência em regiōes de clima tropical, principalmente em focos endêmicos localizados nas zonas central e meridional do Brasil abrangendo os Estados de Mato Grosso, Goiás, Minas Gerais, S. Paulo, Rio de Janeiro e Paraná. 5,6

* Professor Adjunto do Departamento de Enfermagem Médico-Cirúrgica da EEUSP, disciplina Enfermagem em Doenças Transmissiveis.

* * Portaria n.॰ 6 de 7 de março de 1979, publicada no Diário Oficial da União no dia 13/3/79. 

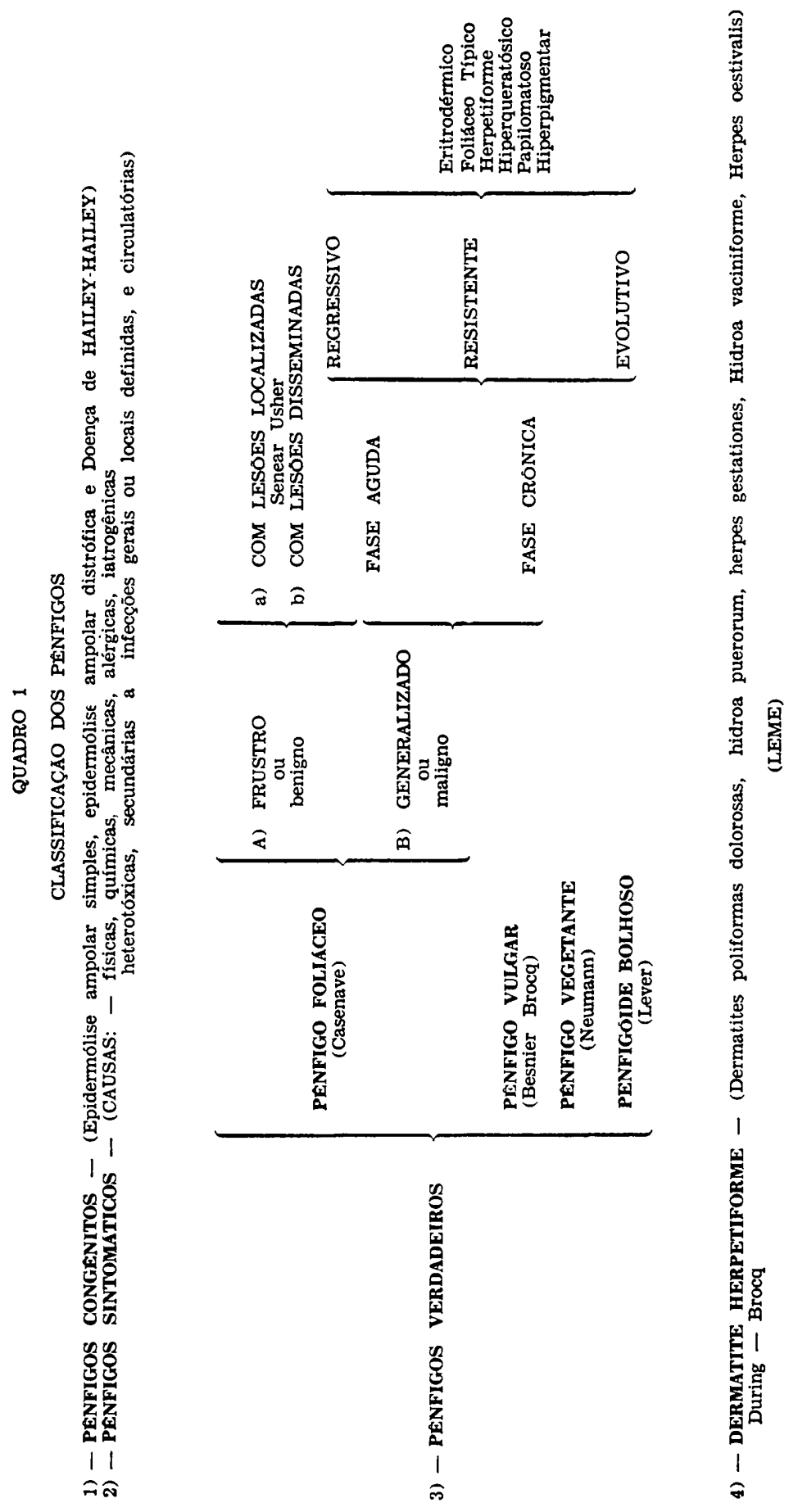
No Brasil, estima-se que anualmente aparecem, em média, 1.000 a 1.500 casos novos, a maioria deles nas localidades acima referidas.

Quanto à etiopatogenia, a teoria mais aceita é a teoria multifásica de LEME ${ }^{5}$. Segundo essa teoria existem: um fator extrínseco, possivelmente viral; o vetor de transmissão e um fator intrínseco dis-reativo (imunológico), como mostra o quadro 2 .

QUADRO 2

ETIOLOGIA E PATOGENIA. DO PENFIGO FOLIACEO

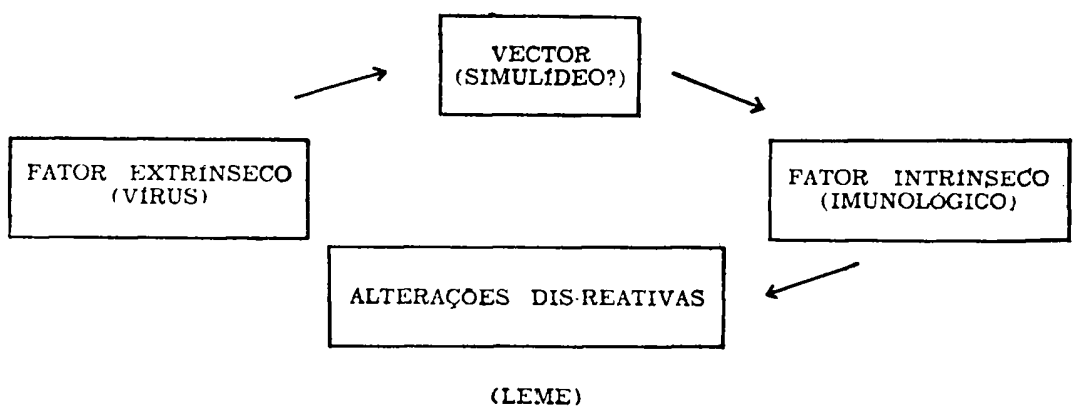

O vírus, intruduzido no organismo humano pelo artrópode (Simulium pruinosum) provoca, em indivíduos com susceptibilidade imunológica, alterações disreativas do tipo auto-agressão imunológica, resultando então as lesões do Pênfigo.

0 vetor de transmissão, Simulium pruinosum (borrachudo) tem como habitat zonas com altitude de 530 a 900 metros e $76 \%$ de umidade relativa do ar. Por essa razão, existem determinados focos em áreas endêmicas cujas caracteristicas geofísicas favorecem a proliferação daqueles insetos. Os maiores focos localizam-se dessa forma, nos Estados do Centro Oeste do Brasil.

Após a penetração do agente etiológico (virus?) carreado pelo Simulídeo, surgem, no organismo suscetível, respostas dis-reativas com produção de auto-anticorpos evidenciáveis pela imunofluorescência. Esses anticorpos, específicos para o Pênfigo, localizados principalmente na camada de Malpighi, são encontrados em praticamente $100 \%$ dos casos de Pênfigo Foliáceo Sul-Americano.

Além disso, o título de anticorpos está diretamente associado à gravidade do caso; quanto maior a sua titulagem, maior a gravidade da doença.

A evolução do Pênfigo Foliáceo Sul-Americano e seu tratamento são descritos, de forma semelhante, por diversos especialistas ${ }^{5,6,7}$.

$\mathrm{Na}$ fase inicial da doença aparecem microbolhas e eritema, sobretudo na face, região médio-esternal e inter-escápulo-vertebral.

Após a introdução da terapêutica imunossupressora, mais ou menos $50 \%$ dos casos estacionam-se nessa fase, tomando as características de um Pênfigo frustro ou benigno. 
Outros $50 \%$, evoluem para a forma generalizada. As bolhas se alastram cobrindo áreas extensas da face, tronco e membros. As lesões são frequentemente acompanhadas de intensa toxemia e eritrodermia.

Segue-se posteriormente, o periodo de regressão em que se observa a melhora do quadro geral. $O$ processo patológico tende a desaparcer, surgindo no entanto com grande freqüência, manchas escuras na pele decorrentes de alterações melânicas, fenômeno esse chamado de "leopardização".

Quando não ocorre a regressão do processo, advém a fase chamada eritrodérmica crônica, em que se observam queda de defesa orgânica geral e aparecimento de resistência aos corticoídes $(40-45 \%)$; algumas vezes sobrevém a morte. $O$ indice de letalidade era de $35 \%$ a $40 \%$ até 1956 , ou seja anteriormente à introdução do uso desses medicamentos. Hoje está em torno de 0,5 a $1 \%$, graças ao tratamento com a Triancinolona.

Os especialistas alertam que, "quando a doença incide em crianças ocasiona parada do desenvolvimento físico e mental".

A diagnose é feita pela anamnese, pelo exame específico (Nikolsky) e pelos exames complementares.

$\mathrm{Na}$ anamnese é importante a pesquisa das características geofísicas da região de onde procede o paciente, procurando-se detectar possiveis focos da doença. Os dados epidemiológicos são fatos de grande valor na correta elucidação do diagnóstico.

O exame específico para a moléstia é a pesquisa do Sinal de Nikolsky. Friccionando-se a pele com certa pressão, observa-se deslizamento das camadas superficiais sobre a camada espinhosa.

Dos exames complementares, o mais eficaz é a Imunofluorescência com utilização de soro anti-globulina marcado com fluoresceína.

Além dessa prova são utilizados ainda: o exame histopatológico (verificação da presença de vesículas intra-epidérmicas) e o exame citológico ou prova de TZANC (identificação de células acantolíticas no raspado das vesículas, corado pelo método de Leishman ou Giemsa).

$\mathrm{O}$ tratamento é hoje baseado na imunossupressão. $\mathrm{O}$ produto mais utilizado é a Triancinolona ministrada em dose de ataque de $48 \mathrm{mg}$ por dia até o controle do quadro clínico. Em cada 15 dias de tratamento vai-se reduzindo a dose de $8 \mathrm{mg}$. O paciente é mantido hospitalizado até aingir a dose de 8 a $16 \mathrm{mg}$ por dia, podendo então passar a se tratar no ambulatório. Essa dosagem vai sendo diminuída progressivamente até que o doente não necessite mais do medicamento.

Infecçoos secundárias podem, eventualmente, acometer o doente. Para seu tratamento, usam-se antibióticos de largo espectro como a Tetraciclina e Eritromicina, na dose de $1.2 \mathrm{~g} /$ dia.

Os tratamentos tópicos são utilizados para alívio dos sintomas das lesões locais tais como dor e prurido bem como para o conforto do paciente.

São feitos banhos de $\mathrm{KMNO}_{4}$ a $1 / 40.000$ seguidos de aplicação de Vaselina. Pomadas antibióticas são usadas quando há infecção. 
A profilaxia da doença consiste essencialmente na adoção de medidas de controle do vetor e na promoção e manutenção de boas condições de resistência orgânica.

Essas medidas são apresentadas a seguir.

Controle do vetor.

- Melhoria das condições ambientais (drenagem de águas paradas e de terrenos muito úmidos e manutenção de boas condições de limpeza do ambiente a fim de reduzir ou eliminar as condições de vida do Simulídeo).

- Uso de larvicidas.

- Uso de inseticidas de ação residual nas paredes das casas e em águas paradas.

- Desenvolvimento de programas de controle do inseto (rociamento) em focos endêmicos.

- Uso de inseticidas, mosquiteiros ou telas em zonas endêmicas.

- Uso de repelentes.

- Orientação da comunidade local.

- Promoção e manutenção de boas condições de resistência orgânica.

- Adoção de bons hábitos de higiene: pessoal, ambiental e dos alimentos.

- Alimentação nutritiva e equilibrada.

- Repouso adequado e evitar execesso de desgaste físico.

- Manutenção do equilíbrio emocional.

- Utilização de vacinas e outros recursos para prevenção de doenças infecciosas em geral, a fim de evitar queda de resistência imunológica.

- Prevenção e tratamento adequado dos agravos à saúde.

- Notificação de casos diagnosticados à Unidade Sanitária mais próxima a fim de possibilitar cadastramento permanente e estudos epidemiológicos.

\section{O PACIENTE COM PÊNFIGO FOLIÁCEO SUL-AMERICANO E SEUS PROBLEMAS}

Além do desconforto e insegurança inerentes à própria doença, o paciente com Pênfigo Foliáceo experimenta sérios problemas psico-sociais, conseqüentes à intensa lesão da auto-imagem.

Sinais e sintomas da doença

O período de incubação é desconhecido. Acredita-se porém, que ele seja relativamente longo. Os primeiros sinais e sintomas que aparecem são: máculas, pápulas, eritema e microbolhas acompanhadas de dor e prurido, que se espalham na face, região médio-esternal e inter-escápulo-vertebral. 
Essas lesões se alastram posteriormente, podendo atingir toda a face, tronco e membros, e sangram com extrema facilidade.

Freqüentemente surgem febre, toxemia, inapetência e mal estar geral.

No período de recuperação surgem manchas escuras na pele. Esse fenômeno é denominado "leopardização".

Estresse e desconforto devidos à lesão da auto-imagem, dod imagem corporal e de-sorganização da identidade social.

Constituem problemas prioritários o estresse e o desconforto que o paciente experimenta por perceber a lesão na sua auto-imagem, provocada pela doença propriamente dita e pelo tratamento pelos corticosteróides.

Além disso, sua identidade social também se desorganiza significativamente. As percep̧̧ões e cognições sobre si mesmo, como um ser bio-psico-social que vive em interação com outras pessoas tornam-se totalmente desequilibradas.

Desse estado psico-social peculiar decorrem sentimentos de ser "rejeitado", "sujo", "culpado", "temido" e "indesejável aos outros". 4

São motivos de grande preocupação e sofrimento para o paciente, as percepções sociais sobre si mesmo e os conflitos que experimenta por não querer aceitar a doença que na realidade existe, com presença de lesões visiveis a ele e aos outros.

Preocupação com o aparecimento de novos casos na família

O paciente de Pênfigo preocupa-se com a possibilidade de que outros elementos da família possam ter a mesma doença, fenômeno esse semelhante ao experimentado pelos individuos que adquirem doenças contagiosas.

Receio vda própria doença e preocupações com a sua evolução

O receio da doença, do prognóstico, do agravamento do estado e da possibilidade da instalação de complicaçôes e seqüelas está sempre presente.

Tal receịo origina-se à suspeita da doença, aumenta à elucidação do diagnóstico e acentua-se ainda mais quando se instalam as lesões generalizadas.

Problemas relativos ao uso de corticóides

Aos problemas inerentes à própria doença, somam-se os relativos ao uso de corticóides, tais como: instabilidade emocional; agressividade; excessiva passividade; edema, principalmente facial; oligúria; depressão imunológica e baixa de resistência orgânica.

Essa falta de defesa geral torna o paciente, individuo de alto risco.

Desconforto provocado pelo isolamento reverso ou preventivo

A Unidade de Isolamento preventivo é considerada tão estressante quanto a de doenças contagiosas. Há restrição do espaço, da liberdade e da comunicação in- 
terpessoal. $\mathbf{O}$ ambiente é considerado pelos pacientes como "semelhante à prisão", ambiente que "gera angústia, desespero e nervosismo". ${ }^{3}$

Além disso, para a maioria das pessoas, isolamento está associado à maior gravidade do caso.

\section{Insegurança}

A situação de crise inerente à hospitalização é mais intensa quando se trata de Pênfigo, doença grave que acomete a pele e que constitui alvo de estigma social. A imposição de dependência e a perda de autonomia, a incerteza do sucesso do tratamento, a percepção de ameaça à vida e a perspectiva de internação prolongada são fortes componentes que aumentam a insegurança do indivíduo.

\section{Baixa de resistência}

O uso prolongado de altas doses de corticóides provoca a imunossupressão, tornando o paciente muito susceptível a infecções. $O$ doente passa a ser indivíduo de alto risco e necessita ser protegido das agressões por agentes microbiológicos, físicos, químicos e mecânicos.

\section{ASPECTOS BÁSICOS DA ASSISTÊNCIA DE ENFERMAGEM}

Pela análise dos problemas, verifica-se que o desempenho do papel expressivo da enfermeira é de importância capital no atendimento do paciente de Pênfigo. Não menos importante é o papel instrumental, porém este, requerido em menor extensão.

É direiriz básica da assistência de enfermagem a pacientes hospitalizados, independentemente da patologia de que são portadores, a visão do homem como uma unidade sômato-psíquica inserida em determinado contexto social e que apresenta as necessidades humanas básicas afetadas por aquela situação: estar doente e hospitalizado.

As ações de enfermagem devem objetivar o atendimento global do indivíduo, orientadas pelos problemas do paciente que são sinais e sintomas de alteração das necessidlades humanas provocadas pela doença.

HORTA ${ }^{2}$ diz que, por serem as necessidades básicas humanas interrelacionadas, o desequilíbrio de uma afeta as demais, em maior ou menor grau, tanto no nível fisiológico como no psico-social.

O êxito da assistência de enfermagem depende da correta identificação dos problemas do paciente, do planejamento e da implementação de ações para o seu atendimento. ${ }^{4}$

A seguir serão apresentados os principais aspectos da enfermagem ao paciente com Pênfigo Foliáceo.

\section{Isolamento}

- Instalação e manutenção do "isolamento preventivo", enquanto persistirem as lesões. 
Características do isolamento preventivo.

- Quarto individual, com a porta mantida fechada.

- Uso de avental e máscara por todas as pessoas que entrarem no quarto.

- Uso de luvas por todas as pessoas que têm contato direto com o paciente.

- Lavagem das mãos ao entrar e sair do quarto.

- Visitantes - Devem apresentar-se ao Posto de Enfermagem antes de entrarem no quarto.

Um cartão de identificação do isolamento preventivo contendo os ítens acima, deve ser fixado na porta do quarto. No verso desse cartão devem ser enumeradas as condições que podem exigir esse tipo de isolamento tais como: agranulocitose; pacientes com queimaduras extensas; dematites bolhosas; pacientes com linfoma, leucemia ou que recebem terapia imunossupressora.

2. Cuidados relativos ao ambiente e material.

- Promoção e manutenção de ambiente livre de poeira, correntes de ar e de fontes de infecção.

- Limpeza úmida rigorosa e cuidadosa (água, sabão e desinfetante, esterilização de panos de limpeza a cada plantão)

- Limpeza concorrente diária.

- Limpeza terminal à alta do paciente.

- Uso de material esterilizado no cuidado do paciente.

- Provimento de material necessário ao cuidado do paciente em sua unidade.

3. Assistência ao ajustamento do paciente à nova situação.

- Explicação sobre a doença, tratamento e a hospitalização.

- Apoio e atenção.

4. Assistência na admissão do paciente.

- Admissão direta no quarto.

- Verificação das condições do paciente e atendimento aos problemas prioritários.

- Orientação sobre o sistema de isolamento, seu regulamento e outras informações sentidas necessárias pelo paciente.

5. Administração de medicamentos.

- Explicação sobre os efeitos do corticóide.

- Observar efeitos colaterais (edema, oligúria, distúrbios emocionais, etc. .). 
6. Cuidados com a alimentação e hidratação.

- Alimentação hiper-protéica, hiper-vitaminica e hiper-calórica.

- Oferecimento de saladas com vegetais cozidos e de frutas lavadas com água clorada ou cozidas.

- Hidratação cuidadosa.

- Tratamento das lesões da boca (quando necessário), com água bicarbonatada a $\mathbf{2} \%$ e aplicação de xilocaína 10 minutos antes das refeições.

- Criteriosa higiene oral.

7. Controles e observação.

- Sinais vitais.

- Evolução das lesões bolhosas.

- Sinais de infeç̧ão secundária.

- Eliminações.

- Líquidos ingeridos e eliminados.

- Reações comportamentais.

- Efeitos colaterais da terapia imunossupressora.

- Sinais de complicações e de agravamento.

- Queixas e problemas expressados pelo paciente.

8. Higiene.

- Banho de imersão com água esterilizada, morna (temperatura $37 .^{\circ} \mathrm{C}$ ) ou com Permanganato de Potássio a 1:40.000, em banheira forrada com plástico esterilizado.

- Uso de toalhas e de roupas esterilizadas.

- Aplicação de vaselina esterilizada ou pomada de corticosteróide após o banho.

9. Cuidados com a roupa do paciente.

- Uso de roupas esterilizadas.

- Uso de roupas de cama esterilizadas.

- Uso de lençóis de plástico esterilizados a fim de evitar aderências nas lesões.

10. Cuidados especiais.

- Restrição de manipulação do paciente ao mínimo necessário.

- Movimentação cuidadosa. 
- Cuidados com a dor provocada pelas lesões.

- Uso de arco de proteção esterilizado e outros recursos a fim de evitar aderência das lesões à roupa de cama.

- Orientação e encaminhamento sobre atividades ocupacionais compativeis com as condições do paciente.

11. Preparo para alta.

- Orientação do paciente e da familia sobre a doença (natureza, patogenia, tratamento, profilaxia e cuidados), focalizando em especial a importância e a necessidade da continuidade do tratamento após a alta.

12. Preparo da equipe de enfermagem.

- Orientação sobre:

- doença

- tratamento

- profilaxia

- Cuidados ao paciente e família.

- Procedimentos de isolamento preventivo.

O sucesso do tratamento depende, em muito, da compreensão do paciente sobre a sua doença e plano terapêutico bem como de sua participação no tratamento.

À cicatrização completa das lesões, o doente poderá sair do isolamento preventivo e participar cada vez mais no seu auto-cuidado.

Na fase de recuperação é de extrema importância a orientação do paciente sobre a continuidade do tratamento após a alta, retorno periódico para avaliação médica e sobre o auto-cuidado com vistas a prevenção de complicações, recidivas ou recrudescências da moléstia.

KAMIYAMA, Y. Basic aspects of the nursing care for the patients with South American Pemphigus Foliaceus. Rev. Esc. Enf. USP, São Paulo, 15(3):257-266, 1981.

The author analysis the problems of the South American Pemphigus Foliaceus, its epidemiology, diagnosis, treatment and prophilaxie. She presents the main needs of the patients with that disease and the basic aspects of the nursing care.

\section{REFERENCIAS BIBLIOGRAFICAS}

1. CONTROLE DE INFECÇós NO HOSPITAL. Săo Paulo, Sociedade Beneficiente São Camilo, 1976. $203 \mathrm{p}$.

2. HORTA, W. de A. Necessidades humanas básicas: considerações gerais. Ene. Novas Dimens. São Paulo, 1 (5): 266-8, nov./dez. 1975.

3. KAMIYAMA, Y. \& NAKAZAWA, C. K. Percepção do paciente contagioso sobre a sua doença e o isolamento. Ene. Novas Dimens. São Paulo, 3 (1): 56-63, jan/fev, 1977.

4. KAMIYAMA, Y. Assistência centrada na identidade social: aspectos do cuidado de enfermagem a paciente de hepatite infecciosa. São Paulo, 1979. (Tese de Livre Docência - Escola de Enfermagem da USP).

5. LEME, C. A. Consideraçōes sobre a etiopatogenia do pênfigo foliáceo: esquema de tratamento. Rev. Paul. Med., São Paulo 47 (5): 546-54, nov. 1955.

6. LEME, L. E. \& COIMBRA, M. A. Pénfigo foliáceo brasileiro. Rev. Med., Săo Paulo, 59: 73-81, 1975.

7. SAMPAIO, S. de P. A. Erupções vesico-bolhosas. In: — Dermatologia básica São Paulo, Artes Médicas, 1974. cap. 9. p. 61-64. 